\title{
Education and Research
}

Now that the Education Committee of the South African Society of Physiotherapy is considering proposals for changes to the basic physiotherapy degree curriculum, it may be of interest to note recommendations concerning the basic medical curriculum which were made at the Congress of the South African Association for Medical Education, held in May 1985.

At the Congress, five working groups discussed previously identified national problems.

\section{The end-product}

The term "core" doctor was preferred to that of "basic" doctor. "Core implies that the newly graduated doctor requires further vocational training for whatever $\lambda$ field he wishes to enter, including that of general practice. Emphasis was placed upon communication skills, holistic management, acknowledgement of limitations, awareness of the need for continuing medical education, the role of the doctor as an educator, and commitment to all the inhabitants of Southern Africa.

\section{Recommendations}

- All medical schools in South Africa should aim at training similar core doctors.

- Training objectives should be structured to meet the health needs of the community.

- All medical schools and all training facilities must be open and every effort should be made to eliminate barriers.

- Vocational training is essential for the core doctor - he is not ready for independent practice.

- There is merit in an intermediate degree; variation in course time and streaming other than that is considered highly undesirable.

\section{Selection of students}

It was felt that research was necessary into the selection process, and recommendations concerning this were made as well as recommendations concerning immediate action to be taken by the Medical Schools.

\section{Recommendations -}

- Research is needed into -

1. the health manpower needs of the South African community

2. factors which determine career choice and location of subsequent medical practice

3. the potential use of psychometric tests in the selection of medical students

4. the possibility of taking a bachelor's degree in medical science prior to entry to medical school.

- Action needed by medical schools -

I. an increase in the number of African and Coloured entrants to all South African medical schools
2. the selection of students should be a dynamic process, not a static procedure.

\section{The curriculum}

The term curriculum was taken to include the entire range of learning activities planned for the student. Discussion centred upon the relevance of the curriculum to community needs, problems of overload, who should determine the curriculum and who should teach.

\section{Recommendations -}

- The balance between curative medicine and tertiary care on the one hand, and preventive care and primary health care based on the holistic approach to the patient and community on the other hand, must be restructured to become community oriented, comprehensive health care.

- The curriculum must be problem-based, not subjectbased, and should provide experience in problemsolving.

- The curriculum should be integrated and learnerbased.

- Student assessment must be modified to be compatible with this type of education.

- The core knowledge that the student is expected to know must be clearly defined.

- Post-graduate vocational training must be used to prepare the core doctor for future careers, including general practice.

- Teachers must be trained in the required teaching methods; Medical Faculties must make provision for teacher training geared to individual needs and should provide facilities for staff development; Heads of Department are responsible for ensuring staff development.

\section{Medical educators}

\section{Recommendations -}

- Medical faculties should be approached to recognise that the teaching and learning function is of equal importance with research and service.

- Faculties and the MRC should be requested to recognise research and development in medical education as valid fields for research and funding. Applications for the use of such funds should be screened by a committee with specific expertise in the methodology of educational research and development.

- Educational expertise, development and publications should be given equal weight with clinical research expertise and publications in appointments and promotions.

- Due to the unique problems faced by medical teachers and students and the unique structure of medical education, every medical faculty should establish and support logistically and financially an educational research and development system. 


\section{Self-directed learning}

It was recommended that student-directed learning be promoted in all faculties at all levels since the advantages of this system of learning appear to be much greater than those of the traditional approach. Self-directed learning:

- Leads to understanding of study material and better recall of principles.

- Encourages improved study habits and better utilisation of time.

- Increases student motivation, which may reflect on teacher performance and satisfaction.

- May contribute towards reducing the risk of curriculum overload.

- Helps students to acquire problem-solving skills which forms a basis for lifelong continuing medical education.

- Enables students to learn in their own time and at a pace appropriate for the individual.

- Enables students to develop communication and teaching skills.

- Enables weak students to be recognized earlier.

This report is published with acknowledgements to the Bureau for Medical and Dental Education, University of Stellenbosch.

S.I-C.

At the 1985 Meeting of the Council of the South African Society of Physiotherapy, Council adopted in broad outline a set of long-term objectives for the growth of the Society. One section of objectives was concerned with research. Council also passed an Amendment to the Constitution providing for members of the National Executive Committee to be nominated and elected to represent certain categories of interest. One of these covers Research. Although this Amendment will only become effective at the 1987 Council Meeting, members of the present National Executive Committee have been allocated specific portfolios. The holder of the Research portfolio is also a member of the Education Committee, a Standing Committee of the S.A. Society of Physiotherapy.

The purpose of this report is to outline the detailed objectives which the National Executive Commitee has approved with regard to research, and to comment on progress made so far.

The overall objective is to encourage the development of on-going research programmes which will provide the scientific basis and academic grounding for future physiotherapy education and practice. In order to achieve this it is necessary -

1. To establish a body of physiotherapists skilled in research methodology and statistical analysis

2. To encourage co-ordination and interaction between researchers

3. To establish a fund for research in physiotherapy.

For each of these long-term objectives, intermediate objectives and short-term goals have been formulated. There is obviously some overlap between objectives and several of the short-term goals will serve more than one intermediate objective.

1. The establishment of a body of physiotherapists skilled in research methodology and statistical analysis.

Intermediate objectives

- to establish undergraduate programmes on research methodology and scientific writing

The eight existing universities have been invited to submit their present research methodology curriculum and their ideas on future development. Most have already done so and recommendations will be discussed at the next meeting of the Education Committee.

Most universities encourage student research projects in the final year. The results of successful student projects are already published in the Journal, and it has been proposed that a two-yearly supplement of reprints of student research articles be published, with a prize for the best research article.

- to encourage research by qualified physiotherapists

- to identify present and future research areas

- to promote publication of research findings.

During 1986, two issues of the Society's Journal will be devoted to research. Amongst others, subjects covered will include information sources in physiotherapy, the critical evaluation of research literature, the choice of research methods, problems of bias and writing for publication.

In addition, material is being prepared for a one-day introductory seminar on research, which could be given at different centres in the Republic, as well as for more detailed follow-up workshops on different aspects of research. It is also hoped to establish a panel who could screen articles and give advice prior to submission for publication, as well as act as adjudicators for the proposed award for the "Research Article of the Year".

- to create awareness of existing resources and advisory services available to researchers.

The existing facilities have been investigated and will be listed in one of the two issues devoted to research. A bibliography of books and articles on research methodology, in particular related to physiotherapy, has also been compiled for publication.

- to investigate other means of promoting research The feasibility of awards such as the Fellowships of the Chartered Society of Physiotherapy and the Australian College of Physiotherapists is being studied within the South African context.

The remaining two long-term objectives related to research will be analysed in a subsequent issue of the Journal. Copies of the detailed objectives, and shortterm goals are available from the National Executive Committee and comments would be welcomed. Requests and comments should be addressed to the Research Portfolio, National Executive Committee, P.O. Box 47238, Parklands, Johannesburg 2121.

S. Irwin-Carruthers Research Portfolio 